\title{
Adult Still's Disease with Myocarditis and Peritonitis
}

\author{
Shigeru Hosaka, Naoya Takashina, Akira Ishikawa, Hirobumi Kondo and Sadao Kashiwazaki* \\ A 26-year-old woman had myocarditis and peritonitis during an acute multisystem attack of \\ Still's disease. To our knowledge, these complications are rare manifestations of adult Still's \\ disease. Treatment with high-dose adrenocorticosteroids was rapidly successful in controlling \\ these manifestations. \\ (Internal Medicine 31: 812-815, 1992)
}

Key words: systemic JRA, abdominal pain, heart failure, high-dose adrenocorticosteroid

\section{Introduction}

Adult Still's disease is known as systemic-onset juvenile rheumatoid arthritis in the adult and has been recognized as a cause of fever of unknown origin (1). Most patients have presented with high spiking fever, evanescent maculopapular rash, myalgia, and polyarthritis associated with leukocytosis. Some cases exhibit a wide variety of extra-articular manifestations. Abdominal pain in Still's disease has been attributed to hepatomegaly, lymphadenitis, or peritonitis (2-4), although there is no documented evidence of peritonitis (5-7). Myocarditis may lead to congestive heart failure and arrhythmias in childhood Still's disease $(8,9)$, but these manifestations have rarely been reported in adult patients $(10,11)$. Here we describe a patient with adult Still's disease with clinically significant peritonitis and myocarditis.

\section{Case Report}

A 26-year-old woman presented with high fever, sore throat, myalgias, chest pain, and polyarthralgias. She had a history of pleuritis at age 6 and meningitis at age 8 . She had recurrent fever, sore throat, and polyarthralgia from age 7 to age 14 , and she occasionally developed knee joint swelling.

Two weeks prior to her admission to our hospital, she had a high fever and sore throat. Oral antibiotics had no effect. Chest pain, polyarthralgias, and myalgias developed one day later and she was admitted to another hospital. Despite intensive treatment using various antibiotics, the patient exhibited a labile fever, and diffuse urticaria-like rash. Prednisolone (PSL) $80 \mathrm{mg}$ daily initially reduced her fever. After the dose of PSL was reduced to $40 \mathrm{mg} /$ day, her symptoms were worsened along with dyspnea and vague abdominal fullness. Chest radiograph revealed cardiac enlargement and bilateral pleural effusion. Abdominal CT examination showed splenomegaly, ascitic fluid, and a small mass in the pelvis. She also exhibited thrombocytopenia $\left(44,000 / \mathrm{mm}^{3}\right)$ and disseminated intravascular coagulopathy was suspected. She was referred to our hospital. Figure 1 shows the clinical course of the patient.

Temperature on admission was $39.2^{\circ} \mathrm{C}$ with a pulse of $80 / \mathrm{min}$. The blood pressure was $110 / 50 \mathrm{mmHg}$. A maculopapular rash was observed over the extremities and trunk during temperature elevations. A few small, non-tender axillary lymph nodes were palpable. Examination of the pharynx revealed mild congestion with diffuse erythema. A grade 2 systolic murmur was heard. Dullness and moist rales were present at both lung bases. Her abdomen had diffuse rebound tenderness with hypoactive bowel sounds. No organomegaly or masses were palpable. Peripheral edema was present in her extremities. Active synovitis was present in both wrists. Neurologic examination was negative.

The urine gave $2+$ test for protein and occult blood; the sediment was normal. Repeated examinations of urine were normal. A stool specimen was negative for occult blood. Arterial blood gas analysis showed $\mathrm{pH}$ 7.51, $\mathrm{PCO}_{2} 34.4$ Torr, $\mathrm{PO}_{2}$ 64.0 Torr, and $\mathrm{HCO}_{3}$ $27.3 \mathrm{mmol} / 1$. The white-cell count showed leukocytosis with neutrophilia; the hemoglobin was $10.3 \mathrm{~g} / \mathrm{dl}$; the platelet count was $153,000 / \mathrm{mm}^{3}$. The prothrombin time and the partial thromboplastin time were normal and the fibrinogen was $534.4 \mathrm{mg} / \mathrm{dl}$. The erythrocyte sedimentation rate was $62 \mathrm{~mm} / \mathrm{h}$. Other laboratory values

From the Department of Internal Medicine, School of Medicine, Kitasato University, Sagamihara, *the Institute of Rheumatology, Tokyo Women's Medical College, Tokyo

Received for publication September 10, 1991; Accepted for publication February 26, 1992

Reprint requests should be addressed to Dr. Shigeru Hosaka, the Department of Internal Medicine, School of Medicine, Kitasato University, 1-15-1 Kitasato, Sagamihara 228, Japan 


\section{CLINICAL COURSE}

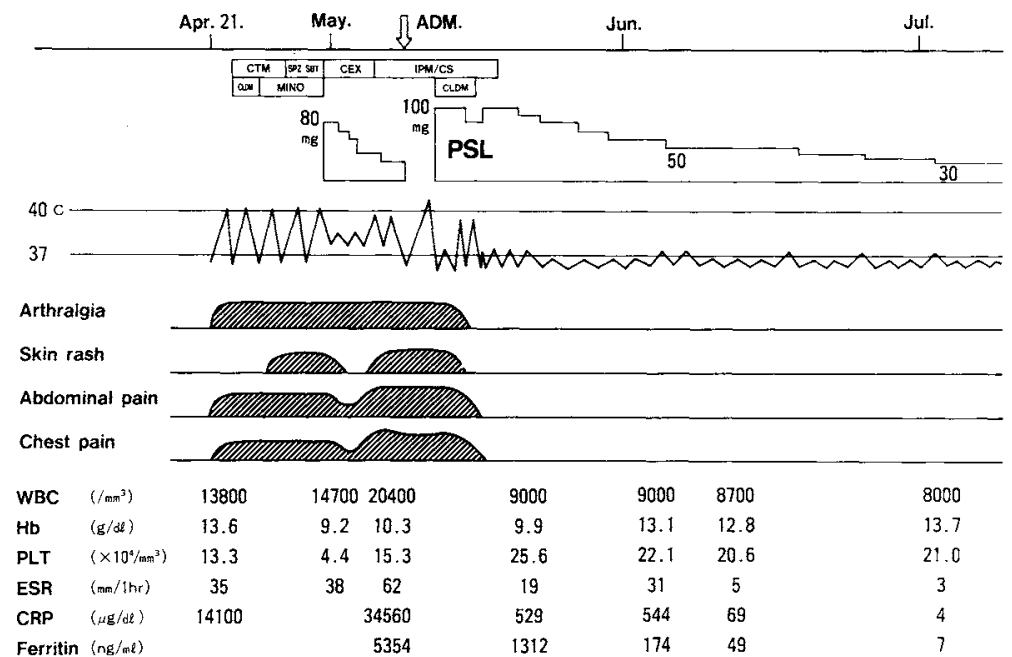

Fig. 1. Summary of the patient's clinical course (symptoms, therapy received, and laboratory data). ADM: admission to our hospital, CTM: cefotiam, SPZ/SBT: sulperazon/sulbactam, IPM/CS: imipenem/cilastatin sodium, CLDM: clindamycin, MINO: minocyclin, PSL: prednisolone.

included: Serum protein $5.9 \mathrm{~g} / \mathrm{dl}$ (albumin 46.4 percent and globulin 30.4 percent), total bilirubin $1.2 \mathrm{mg} / \mathrm{dl}$, GOT 36 IU/1, GPT 10 IU/1, LDH 742 IU/1, ALP 219 IU/1, $\gamma$-GTP $18 \mathrm{IU} / 1$, CPK $28 \mathrm{IU} / 1$, amylase $61 \mathrm{IU} / 1$, aldolase $11.5 \mu \mathrm{g} / \mathrm{dl}$, urea nitrogen $25 \mathrm{mg} / \mathrm{dl}$, creatinine $1.2 \mathrm{mg} / \mathrm{dl}$, sodium $136 \mathrm{mmol}$, potassium $3.9 \mathrm{mmol}$, and chloride $102 \mathrm{mmol}$. Ferrous ion was $16 \mu \mathrm{g} / \mathrm{dl}$ but the ferritin level was $5,354 \mathrm{ng} / \mathrm{ml}$ (normal 2 to $150 \mathrm{ng} / \mathrm{ml}$ ). The C-reactive protein was $34,560 \mu \mathrm{g} / \mathrm{dl}$. Laboratory tests were negative for antinuclear antibodies, rheumatoid factor, cryoglobulins, STS, and precipitating antibodies to Sm, RNP, Ro, or La antigens. Antistreptolysin-O (ASO) and antistreptokinase (ASK) were within normal limits. The $\mathrm{C} 3$ and $\mathrm{C} 4$ levels were 47 and $13 \mathrm{mg} / \mathrm{dl}$, respectively (normal 64 to $125,12.5$ to $35.0 \mathrm{mg} / \mathrm{dl}$ ). Cultures of throat, blood, urine and stool were negative. An electrocardiogram showed nonspecific ST-segment and T-wave abnormalities. X-ray films of the chest revealed cardiac enlargement and bilateral pleural effusion. X-ray films of the abdomen showed dilated loops of small bowel with air fluid levels. All radiographic examinations of joints were normal. An echocardiographic study demonstrated left ventricular hypokinesis and a decreased ejection fraction $(44.8 \%)$ without pericardial effusion (Fig. 2A). Thallium 201 cardiac scintigraphy revealed heterogeneous accumulation in the myocardium. An abdominal CT scan and sonographic study showed splenomegaly, ascitic fluid, and a small mass within the pelvis (Fig. 3). Initial therapeutic attempts with antibiotics were unsuccessful. She continued to have the spiking fever accompanied by the rash.

A clinical diagnosis of adult Still's disease was made on the fourth hospital day, and PSL treatment of $100 \mathrm{mg}$

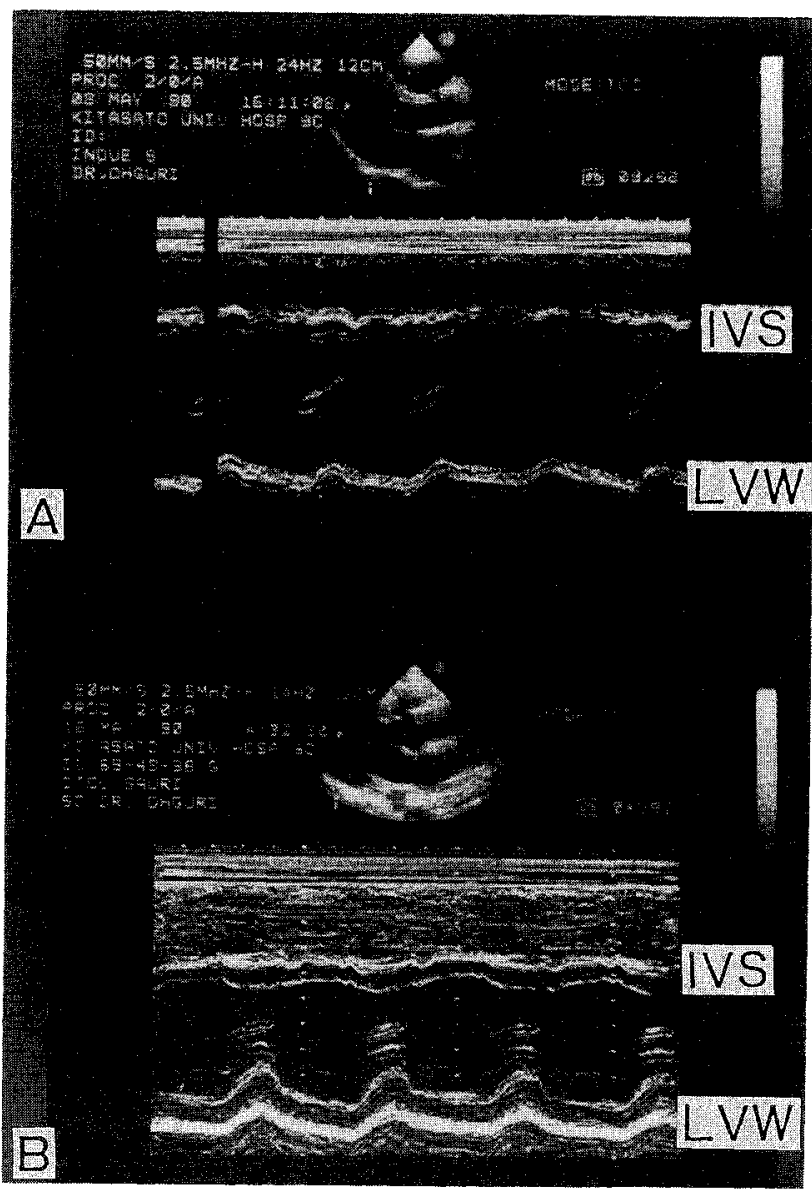

Fig. 2. A) M-mode cchocardiogram before treatment shows decreased left ventricular (LV) contractility (ejection fraction $=44.8 \%$ ) without pericardial effusion. B) At follow up after prednisolonc treatment, normal septal and left ventricular contractility arc present. IVS: interventricular septum, LVW: left ventricle wall. 


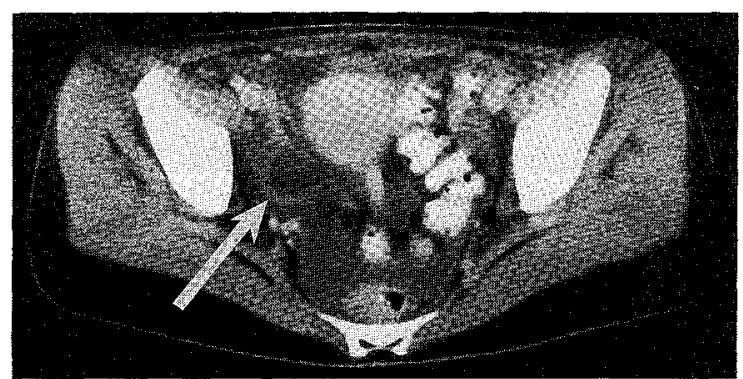

Fig. 3. Computcd tomography of the pelvis shows ascitic fluid and a small mass to the right of the uterus, suggestive of lymphadenopathy (arrow).

daily was started. The heart failure, peritonitis and systemic symptoms cleared rapidly and the echocardiogram reverted to normal (Fig. 2B). The ascitic fluid and pelvic mass resolved and the hematological abnormalities also normalized. The patient remained well with a gradual tapering of the PSL dosage.

\section{Discussion}

Adult Still's disease has attracted increasing interest since the initial report of Bywaters (12). Soon thereafter, this disease became recognized as a cause of fever of unknown origin (1). A recent review emphasized that high fever, arthritis, maculopapular rash, leukocytosis, increased ESR, negative tests for antinuclear antibody and rheumatoid factor, and ferritinemia are the most prominent clinical features $(2-4,13)$. More important however, exclusion of other febrile diseases is indispensable in the diagnosis of Still's disease. In the present patient, the extensive evaluation, serological evidence and negative bacterial studies excluded other possible diseases and most of the characteristic features of adult Still's disease were present. Among the features in the present patient, abdominal pain and congestive heart failure were particularly notable. Abdominal pain in adult Still's disease has been attributed to a variety of causes including hepatosplenomegaly, mesenteric adenitis, and serous peritonitis, although a cause is rarely documented $(2-7)$. In the present case, an abdominal CT scan showed splenomegaly, ascitic fluid, and a small pelvic mass. This pelvic small mass was thought to be lymphadenopathy, because it disappeared after PSL therapy. Abdominal pain is not a rare symptom in Still's disease, but the correlation between peritonitis and the frequency of abdominal pain in Still's disease is not known. The present patient's subjective symptoms were not as severe as the objective findings; subjective are often overshadowed by more impressive systemic features. Abdominal CT scan can be easily performed and should be considered as the investigation method of choice for patients presenting with abdominal pain.

In childhood Still's disease, myocarditis is often as- sociated with pericarditis and may lead to congestive heart failure and arrhythmias (8), but it is rare in adult Still's disease. In the present case, myocarditis was diagnosed by the appearance of congestive heart failure and echocardiographic abnormalities in the absence of pericardial effusion or extracardiac cause. Abnormality of cardioscintigraphy also supported the myocardial injury diagnosis. Two reports discussed histological studies of acute myocarditis with adult Still's disease. One case revealed diffuse interstitial mononuclear cell infiltrates associated with proliferating fibroblasts and immature connective tissue (10), the other case had numerous histiocytes and macrophage infiltration and fibrinoid necrosis appearance of the myocardial vessels (11). Negative evidence of streptococcal infection denied rheumatic fever in the present case. Svantesson et al (8) reported cases of congestive heart failure accompanying aseptic peritonitis in childhood Still's disease. The relationship between myocarditis and peritonitis is unknown.

The study of Japanese patients revealed that nonsteroidal anti-inflammatory drugs alone do not suppress the disease and that moderate doses of steroid are recommended (13). The rapid withdrawal of PSL at the previous hospital may have been the cause of deterioration of this patient. There is no index to determine PSL dosage level in the treatment of Still's disease. The good response to PSL in this patient suggests that high-dose steroid treatment may be indicated in adult Still's disease with severe organ involvement, including myocarditis and peritonitis.

\section{References}

1) Bujak JS, Aptekar RG, Decker JL, Wolff SM. Juvenile rheumatoid arthritis presenting in the adult as fever of unknown origin. Medicine 52: 431, 1973.

2) Reginato AJ, Schumacher HR Jr, Baker DG, O'Connor CR, Ferreros J. Adult onset Still's disease: experience in 23 patients and literature review with emphasis on organ failure. Semin Arthritis Rheum 17: 39, 1987.

3) Larson EB. Adult Still's disease: evolution of a clinical syndrome and diagnosis, treatment, and follow-up of 17 patients. Medicine 63: $82,1984$.

4) Cush JJ, Medsger TA Jr, Christy WC, Herbert DC, Cooperstein LA. Adult-onset Still's disease: clinical course and outcome. Arthritis Rheum 30: 186, 1987.

5) Pollet SM, Vogt PJ, Leek JC. Serous peritonitis in adult Still's syndrome. J Rheumatol 17: 98, 1990.

6) Poralla T, Hutteroth T, Mayet W, et al. Peritonitis and massive granulocytic infiltration of the spleen in adult Still's disease. Z Rheumatol 47: 363, 1988.

7) Bhettay E, Thomson AJG. Peritonitis in juvenile chronic arthritis: a report of 2 cases. S Afr Med J 68: 605, 1985.

8) Svantesson H, Bjorkhem G, Elborgh R. Cardiac involvement in juvenile rheumatoid arthritis: a follow-up study. Acta Paediatr Scand 72: 345, 1983.

9) Garcia JM, Sheridan R, Hanissian AS. Echocardiographic detection of early cardiac involvement in juvenile rheumatoid arthritis. Pediatrics 73: 394, 1984. 


\section{Hosaka et al}

10) Bank I, Marboe CC, Redberg RF, Jacobs J. Myocarditis in adult Still's disease. Arthritis Rheum 28: 452, 1985.

11) Sachs RN, Talvard O, Lanfranchi J. Myocarditis in adult Still's disease. Int J Cardiol 27: 377, 1990.

12) Bywaters EGL. Still's disease in the adult. Ann Rheum Dis
30: 121, 1971.

13) Ohta A, Yamaguchi M, Tsunematsu T, et al. Adult Still's diseasc: a multicenter survey of Japanese patients. J Rheumatol 17: $1058,1990$. 